\title{
CONCEITOS DE BIOCLIMATOLOGIA E SUSTENTABILIDADE APLICADOS A FASE DE PROJETO EM HABITAÇÕES DE INTERESSE SOCIAL
}

Aline Raquel DREHER ${ }^{1}$

Claudio Alcides JACOSKI ${ }^{2}$

Rafael de MEDEIROS ${ }^{3}$

\footnotetext{
${ }^{1}$ Arquiteta, com Pós-Graduação em Desenvolvimento e Tecnologia.

2 Engenheiro Civil, com doutorado em Engenharia de Produção, docente do Programa de Pós Graduação em Tecnologia e Gestão da Inovação da Universidade Comunitária da Região de Chapecó.

${ }^{3}$ Engenheiro Civil, Mestrando do Programa de Pós Graduação em Tecnologia e Gestão da Inovação.
}

Recebido em: 12/07/2015 - Aprovado em: 11/01/2016 - Disponibilizado em: 30/07/2016

\begin{abstract}
Resumo
Este trabalho é motivado pela busca de qualidade de vida das pessoas de baixa renda por meio da elaboração de um conjunto residencial que atenda as necessidades de conforto térmico e lumínico sem elevar os custos da construção, num contexto de edificações sustentáveis, utilizando-se de meios naturais, como o vento, o sol, e a disposição dos cômodos, por meio de normativas brasileiras, harmonizando a construção com o clima local, fazendo uso de telhados verdes que garantem uma maior qualidade do ambiente, além de captar as águas das chuvas.
\end{abstract}

Palavras-chave: Bioclimatologia, Telhados Verdes, Projeto Arquitetônico, Habitações de Interesse Social.

\section{Concepts of Bioclimatology and Sustainability Applied in Architectural Design in Social Habitation}

\begin{abstract}
This work is motivated by the pursuit of quality of life of low-income people through the development of a residential complex that meets the needs of thermal and luminous comfort without increasing construction costs in a context of sustainable buildings, using natural resources, like wind, sun, and the layout of the rooms, through Brazilian regulations, harmonizing the building with the local climate, making use of green roofs that provide a high quality environment, and capture rainwater.

Key words: Bioclimatology, Green Roofs, Architectural Design, Housing Social Interest.
\end{abstract}

\section{Introdução}

A atual situação das habitações de interesse social é certamente algo a ser indagado. Pela sociedade pela falta de atenção dada a fase de planejamento e projeto, são ocasionadas em muitos casos moradias que não proporcionam o devido conforto aos usuários.

Este trabalho buscou apontar as diretrizes a serem empregadas para a adaptação de projetos arquitetônicos de moradias de interesse social, com foco na sustentabilidade e, aprimorando os elementos projetuais, aos fatores climáticos, aos conceitos de bioclimatologia e a utilização de telhados verdes, visando um projeto eficiente que possa proporcionar conforto e satisfação ao usuário. Diminuindo o dispêndio de energia artificial adaptando os espaços do projeto às características do meio em que será inserido.

São considerados nos fatores climáticos a composição das características das regiões que determinam ou originam o clima. Dentre os fatores climáticos pode-se citar a radiação solar, a latitude, a altitude, os ventos e as 
massas de ar. Os mais importantes elementos climáticos são radiação solar, latitude, ventos, temperatura, umidade e precipitações, merecendo assim, um estudo mais aprofundado (HERTZ, 1998, apud FRANÇA, CRUCINSKY, 2010).

Os telhados verdes por conta da acelerada urbanização, ganham importância, pois "com o uso e ocupação desordenada do solo, principalmente nas grandes cidades, houve uma grande impermeabilização de áreas antes permeáveis, além de assentamentos urbanos próximos a cursos d'água. A ocorrência de enchentes em grandes cidades está se tornando cada vez mais frequente. A captação e a utilização de água de chuva poderiam se tornar ferramentas importantes, uma vez que contribuiriam para a minimização da ocorrência de enchentes, para a economia de água potável, para a contribuição para o meio ambiente, entre outras vantagens. (CARDOSO, 2009, p. 1)

Para o estudo de caso foi escolhida uma área destinada a construções sociais, localizada na cidade de São Lourenço do Oeste - SC. Sendo identificadas estratégias a serem aplicadas na fase de projeto, para atingir uma residência com melhor desempenho térmico por meio da utilização dos conceitos da bioclimatologia, sempre com base em uma linha de pensamento de inovação.

\section{Habitações de Interesse Social no Brasil}

A questão habitacional no Brasil continua sendo um problema enfrentado há décadas, agravado pelo êxodo rural, pelas grandes taxas de crescimento demográfico e por um gradativo aceleramento do processo de urbanização, principalmente, das grandes metrópoles brasileiras. Esse problema se agravou na segunda metade da década de 70 , quando se notou uma grande reversão do crescimento econômico, que se refletiu na redução da oferta de empregos e, por consequência, na diminuição do poder aquisitivo da população. Em decorrência disso, verificou-se um grande crescimento migratório da população em direção as grandes cidades. (MELLO, 2004, p. 16)

A temática da habitação social é certamente uma das mais relevantes no cenário urbano, dado o reconhecido déficit no setor, estimado hoje no Brasil em quase oito milhões de famílias (MINISTÉRIO DAS CIDADES, 2006, apud ROTTA, 2009, p.21). Sem dúvida, é premente a necessidade de se produzir em larga escala novas unidades habitacionais, porém a pouca estruturação dada à fase de projeto e de especificação técnica tem gerado edificações de baixa qualidade construtiva, totalmente desvinculadas as questões de conforto, tanto térmico quanto acústico.

No Brasil, verifica-se que os programas para habitação de interesse social vem sendo implementados em todo o território nacional de forma padronizada, sem haver uma preocupação com especificidades regionais, principalmente no que diz respeito a avaliação do desempenho térmico das moradias. (ROTTA, 2009, p.21)

O setor da habitação traz também outro grande problema a ser enfrentado em nosso país, em especial à população de baixa renda: o desenvolvimento socioeconômico desigual da sociedade acarreta um grande déficit de moradias dignas e de qualidade para famílias de baixa renda.. Por este motivo, muitas pesquisas têm procurado revelar os benefícios que a arquitetura bioclimática oferece ao setor da habitação social, por ser uma alternativa economicamente viável. (CUNHA; CASTRO; GUIMARÃES; BUZATTO, 2012)

É preciso resgatar o conhecimento presente na história da arquitetura de que o homem dispunha para obter um razoável nível de conforto na edificação sem que fosse despendida uma grande quantidade de energia. Muitos dos conhecimentos existentes na antiguidade relacionados à utilização dos recursos naturais e aproveitamento das características desejáveis do clima se perderam no tempo. (GELLER, 1994 apud CUNHA; CASTRO; GUIMARÃES; BUZATTO, 2012) 
Para Mascaro (1992 apud ROTTA, 2009, p.21), o generalizado desconhecimento das condições climáticas por parte dos projetistas e o baixo prestigio das soluções de acondicionamento natural ficam evidenciados pelos grandes e frequentes erros de projeto encontrados. Segundo ele, os erros em projetos são frequentes na forma e disposição dos locais, na altura dos edifícios, na sua orientação, na composição dos materiais e, sobretudo, nas suas coberturas.

A satisfação do usuário com a moradia, geralmente está ligada aos indicadores de conforto ambiental (térmico, visual, acústico, aspectos de funcionalidade do espaço e qualidade do ar). Decisões tomadas nas primeiras fases do projeto arquitetônico, tais como: volumetria do edifício, orientação das fachadas, posicionamento e sombreamento de janelas, sistemas construtivos e coberturas e das propriedades dos elementos que $\mathbf{o}$ compõem também influenciam no desempenho térmico. As temperaturas dos ambientes internos dependerão do efeito conjugado destes diversos parâmetros e o clima de cada lugar. (ROTTA, 2009, p.40)

Devido ao grande território, o Brasil possui uma grande variação no clima, acarretando características diferenciadas para os projetos nas diferentes regiões do país. A NBR 15220/ABNT (Associação Brasileira de Normas Técnicas, apud ROTTA, 2009, p.31) trata do desempenho térmico de edificações. $\mathrm{Na}$ parte 3 da norma é abordado o zoneamento bioclimático brasileiro, e mediante a aplicação de uma adaptação do Diagrama Bioclimático de Givoni (1992 apud ROTTA, 2009, p.31), foi classificado o clima de cada célula, agrupando-as conforme as Zonas Bioclimáticas.

\section{A Necessidade do Uso Racional da Energia}

$\mathrm{O}$ uso e a produção de energia se constituíram atualmente como fatores de sobrevivência para a economia global, uma vez que todo o setor produtivo, além das demais condições da vida contemporânea, depende diretamente do uso de energia.

Hoje, depois de um longo período de uso intensivo (e irreflexivo) de energia operante, e com a instalação de uma crise de energia, estabelecida a nível mundial, construir edificações apoiadas em projetos sintonizados com o clima local, já não é mais uma posição ecológica, idealista ou contestatória. É uma necessidade quando se analisa o panorama mundial da evolução do consumo em relação a disponibilidade de energia. (MASCARÓ, 1991)

É portanto condizente com a atual situação, que não somente grande edificações passem por controle e certificação ligadas ao uso racional de energia, mas sim toda e qualquer obra gerada pela construção civil.

\section{A Arquitetura de Edificações Sustentáveis}

Sustentabilidade pode ser definida como sendo a capacidade de utilizar os recursos básicos, necessários para manter a sociedade, sem prejudicar futuras gerações na satisfação de suas próprias necessidades, segundo Silva (2005). Preservar os recursos, compatibilizando os interesses das gerações presentes e as necessidades das gerações futuras é algo que o ser humano, pela sua condição de ser dotado de inteligência, deve almejar.

A responsabilidade da arquitetura frente ao meio ambiente impõe, portanto, o desafio de projetar e construir edifícios que consumam menos materiais, água e energia que os atuais. Para isso é necessário que os profissionais da área ampliam seu conhecimento principalmente no que tange à incorporação de informações ambientais em seus projetos. (PINTO, 2009, p.21)

\subsection{A Arquitetura Bioclimática}

Por meio de um estudo da bioclimatologia ramo do conhecimento que relaciona o clima aos seres vivos - aplicado à arquitetura, pode- 
se estabelecer projetos arquitetônicos que priorizem estratégias naturais, tentando utilizar o menos possível os sistemas de climatização e iluminação artificial, minimizando custos do empreendimento, de manutenção e operação, aspectos fundamentais quando se trata de habitação de interesse social. (CUNHA; CASTRO; GUIMARÃES; BUZATTO, 2012)

A arquitetura bioclimática constitui-se de uma arquitetura adaptada ao meio ambiente, sensível ao impacto que provoca na natureza e que procura minimizar o consumo energético, e a degradação ambiental. (FRANÇA, CRUCINSKY, 2010)

A arquitetura bioclimática possui formas arquitetônicas diferentes para atender às necessidades humanas em cada uma das diferentes regiões climáticas. É a arquitetura que utiliza as condições climáticas oferecidas pelo ambiente para atender às necessidades básicas do ser humano nas suas construções. (CLIMACO, 2008, apud FRANÇA, CRUCINSKY, 2010)

A NBR 15220-3 dividiu o país em regiões com uma relativa homogeneidade climática. Para tanto, foi utilizada a base de dados climáticos do Brasil, com os dados de médias mensais das: temperaturas máximas, temperaturas mínimas, e umidades relativas do ar. Das 330 cidades, de diferentes posições geográficas, algumas foram classificadas a partir de dados registrados em décadas de apuração, enquanto outras localidades foram ordenadas por interpolação dessas informações. (BAGNATI, 2013, p.44)

A NBR 15220 (2003) subdivide o território em oito zonas homogêneas quanto ao clima, formulando indicações técnico-construtivas que otimizam o desempenho térmico das edificações, através da melhor adequação climática, fazendo recomendações de diretrizes construtivas e detalhamento de estratégias de condicionamento térmico passivo, baseados em parâmetros e condições de contorno, apresentando também recomendações quando ao desempenho térmico de habitações unifamiliares de interesse social aplicáveis na fase de projeto.
É, portanto, condizente com a atual conjuntura energética mundial, que independente da dimensão da edificação, seja sempre que produzido o projeto arquitetônico, aplicados os conceitos da Arquitetura Bioclimática, pois ao mesmo tempo em que se atua de forma global na conservação do meio ambiente, se interfere de maneira local nas condições de bom uso da obra de moradia.

A figura 01 dispõe a divisão das oito diferentes zonas que compreendem o zoneamento bioclimático brasileiro, com a indicação da localização da cidade de São Lourenço do Oeste (SC), local do estudo.

Figura 1 - Zoneamento Bioclimático Brasileiro

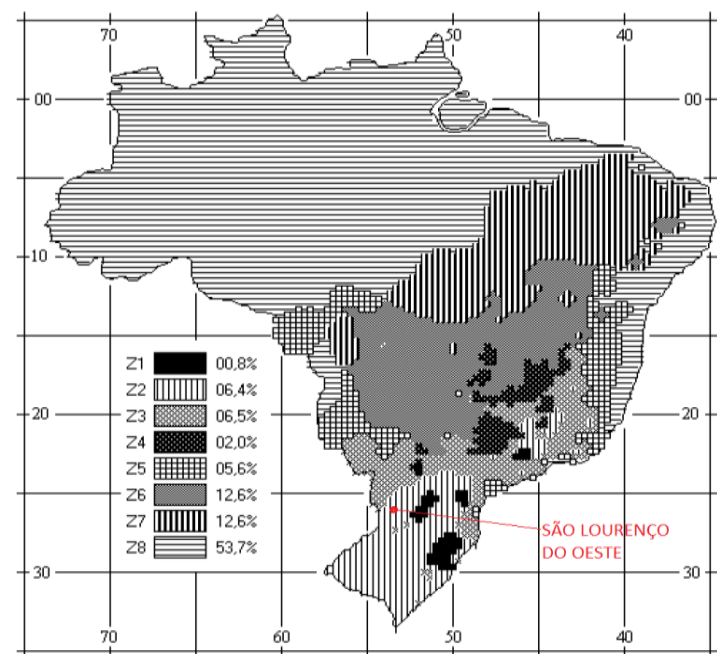

Fonte: NBR 15220 (2003)

A arquitetura bioclimática, ou de alta eficiência energética, está se convertendo no pilar de aproveitamento da energia renovável, mediante adequação do projeto, geometria, orientação e construção do edifício, bom como as condições climáticas de seu entorno. $\mathrm{A}$ adequação climática e ambiental não deve se entender como um elemento a mais de um processo de projeção arquitetônica predeterminada; e o projeto que deve adequar-se as solicitações do meio natural e a todos os demais condicionantes de partida, aproveitando as possibilidades que lhe são oferecidas. (PINTO, 2009, p.39)

Uma orientação solar cuidadosa aliada a uma boa localização dos cômodos contribui muito na melhoria das condições de conforto 
térmico. A correta distribuição de aberturas pode facilitar a ventilação cruzada, bem como o ganho de calor solar no inverno. Para GOULART (1993, apud ROTTA, 2009, p.41), os dispositivos de sombreamento devem ser usados de maneira a evitar a penetração de radiação solar durante o verão e permitir a entrada de radiação, aquecendo passivamente os ambientes, no inverno. (ROTTA, 2009, p.40)

\subsection{Telhados Verdes}

Os telhados verdes, também denominados de coberturas verdes, são áreas vegetadas sobre casas ou edifícios residenciais, industriais, comerciais ou públicos. A vegetação pode ser rasteira, arbustiva ou de porte arbóreo. Dentro da arquitetura, por alguns é considerada como o futuro do urbanismo, para os geógrafos pode-se dizer que é a possibilidade para minimizar os efeitos do aquecimento no microclima urbano (CATUZZO, 2013, p. 60).

Segundo Tomaz (2007 apud CARDOSO, 2009, p. 9), edificações com telhados verdes apresentam, em média, retenção de $15 \%$ a $70 \%$ das águas pluviais, possibilitando redução nos picos de enchentes; redução da temperatura do telhado no verão em mais de 40\%; redução dos extremos de temperatura e minimização das "ilhas de calor" causadas pela quantidade excessiva de prédios que impermeabilizam as áreas que antes eram permeáveis. Além disso, o custo de implantação de um telhado verde também é um incentivo, pois varia de 30 a $50 \%$ do custo de uma estrutura sem vegetação. A implantação de um telhado verde suscita a necessidade de implantação de uma camada impermeável inferior que impeça a infiltração de água na laje, um sistema de drenagem eficiente que permita o escoamento da água e a não acumulação em locais impróprios, e adequada vegetação para resistir às diferentes temperaturas. Além disso, deve-se escolher espécies vigorosas e tolerantes ao solo seco e manter uma espessura de solo entre 150 e 300mm (TOMAZ, 2007 apud CARDOSO, 2009, p. 9).
Outra opção é a utilização de resíduos de demolição triturados, como: pedras, tijolos e concreto, por consistir em alternativa viável para implementação como sistema de drenagem em meio ao substrato, na cobertura verde. Além disso, apresentam benefícios na escala ambiental, pois incluem reaproveitamento de materiais e reduzem a necessidade de transporte e disposição final dos resíduos da construção (GREEN, 2006, apud LOPES, 2007, p.38-39).

São vários os benefícios que as áreas verdes proporcionam, tais como: a função ecológica, a função estética, o suporte à biodiversidade, ajudando na saúde mental e física dos indivíduos, além de fornecer referências subjetivas e espaços coletivos ao lugar (GREEN, 2004, apud LOPES, 2007, p.42).

\section{Diretrizes Construtivas Na Fase Do Projeto}

Relacionar o clima do local com a prática projetual deveria ser uma premissa para qualquer projeto. Porém, os avanços tecnológicos presenciados no final do século XIX e início do século XX levaram gerações de arquitetos a acreditar que o uso de equipamentos e máquinas para o condicionamento dos ambientes resolveria as questões relacionadas ao conforto térmico das edificações. Na década de 70 , a crise do petróleo serviu como alerta, despertando a consciência de que as fontes de energia utilizadas no condicionamento dos ambientes não eram inesgotáveis, e a retomada de técnicas e conceitos antes utilizados eram necessários. Em 2001, o Brasil sofreu com o "apagão", a pior crise energética da história do país, e a incerteza sobre a disponibilidade de energia num futuro próximo acarretou uma atenção ainda maior sobre o tema. (ROTTA, 2009, p.35)

Para se chegar a um projeto adequando as questões ligadas à bioclimatologia e que possua bom desempenho térmico, devem ser seguidas algumas estratégias de condicionamento térmico passivo, e o projeto deve ser adequado as solicitações do meio em 
que será inserido, para tanto devem ser analisados e estudados alguns fatores, os quais serão descritos a seguir.

\subsection{Aberturas}

Através das janelas é possível ventilar, iluminar, e estabelecer trocas térmicas entre os meios externo e interno, além de proporcionar contato visual. A radiação solar incidente, além de produzir a luz visível, ainda é responsável pelos efeitos térmicos. Brown et al (2004 apud BAGNATI, 2013, p.63) afirma que em uma edificação "o tamanho, o número e a orientação das janelas afetam enormemente o consumo energético". Enquanto Hertz (1998 apud BAGNATI, 2013, p.63) declara que "do ponto de vista funcional, as características das janelas também variam de acordo com as necessidades especificas dos tamanhos dos cômodos e das atividades neles desenvolvidas."

\subsection{Ventilação}

A ventilação natural é produzida de modo espontâneo pelas correntes de ar que fluem no interior da edificação, através de elementos como portas, janelas e telhado. A obtenção de conforto através da ventilação natural pode ser de forma direta ou indireta, mas estará sempre condicionada às características climáticas do local. (COSTA, 2007)

Para o projeto de ventilação do edifício, deve-se ter suficientes informações sobre os ventos locais. Direção, velocidade e frequência dos ventos, possibilidades de vendavais e dias de calmaria são dados fundamentais para o projeto de ventilação natural. (MASCARÓ, 1991)

\subsection{Orientação Solar}

Hertz (1998 apud BAGNATI, 2013, p.80) descreve a importância da orientação solar no projeto de uma edificação: "A orientação de um edifício é determinada por fatores como o vento, a radiação solar e a vista, além da necessidade de privacidade e do controle do ruído circundante." Ainda, afirma que através da orientação é possível calcular a quantidade de radiação incidente em um objeto construído, e que "graças a uma orientação direcional correta do edifício, pode-se obter uma diferença de até $3{ }^{\circ} \mathrm{C}$ entre a temperatura externa e a interna, além de conseguir reduzir a potência da forte incidência da radiação solar durante as horas quentes."

Lamberts et al (2004 apud BAGNATI, 2013, p.80) afirma que, no hemisfério sul, adotam-se os seguintes dados para efeitos de escudo de fachada relativo a posição solar:

- fachada orientada para leste: recebe sol no período da manhã em todas as estações;

- fachada orientada para oeste: recebe sol no turno da tarde e em todas as estações. Diz-se a fachada crítica, que recebe maior quantidade de radiação solar;

- fachada orientada para norte: o sol é mais baixo durante o dia no inverno, e em boa parte da primavera e do outono. Enquanto que, no verso, o sol estará mais alto, incidindo em poucas horas do dia;

- fachada orientada para sul: o sol é inexistente durante o inverno, pouco presente na primavera e outono. Enquanto no verso estará presente no início e final do dia.

\subsection{Iluminação}

O sol é a principal fonte de luz natural disponível para iluminação de ambientes. É de fácil aproveitamento e a operação para sua apropriação geralmente é de baixo custo. Sua utilização para iluminar os ambientes internos de uma edificação se dá, principalmente, através dos elementos como portas, janelas, telhado, clarabóias, ocorrendo de forma direta (incidência) ou indireta (reflexão e/ou dispersão). (COSTA, 2007)

É necessário, porém, que o projeto da edificação garanta níveis adequados de iluminação, sem permitir ganhos térmicos excessivos para o interior do ambiente. Para isso, devem ser consideradas as condições climáticas da região, pois o nível de insolação 
varia com a latitude e a estação do ano, bem como as necessidades de iluminação. Quanto maior a precisão da atividade realizada, maior o nível de iluminação requerido. (COSTA, 2007)

\subsection{Climatização Natural}

O uso da vegetação no entorno para controle da temperatura ambiental além de contribuir para o conforto interno das edificações nas proximidades, contribui também para a preservação e qualidade do meio-ambiente. (COSTA, 2007)

Apesar de serem bastante úteis no controle da temperatura, esses elementos devem ser utilizados de forma equilibrada a fim de não prejudicar a iluminação nos ambientes internos. (COSTA, 2007)

\subsection{Espaços Comuns}

O espaço comum, nos conjuntos habitacionais, é o elemento de transição entre a unidade habitacional e o espaço público. Configura-se, portanto, em um item importante para o desenvolvimento do projeto. (NAVAZINAS, 2007, p.10)

Qualquer que seja a forma, o modelo, o processo de produção ou o público a que se destina um edifício, o denominado "espaço comum" a um componente que pode elevar a qualidade dos conjuntos habitacionais produzidos pelo poder público. (NAVAZINAS, 2007, p.15)

\section{Estudo De Caso Em Projeto De Um Conjunto Habitacional}

O estudo se dá em um projeto de um conjunto habitacional de finalidade social, no formato de residências isoladas duplex, em que cada moradia apresentou como requisito, conter sala e cozinha com conceito aberto para promover a interação dos usuários, lavanderia, banheiro, e dois dormitórios, devendo ser aconchegante e prática, primando pelo conforto térmico e visando a melhor estética dentro das condições de projeto e execução de baixo custo, obedecendo às normas da bioclimatologia, e fazendo uso de telhado verde para obtenção da água da chuva e melhoria do conforto térmico da edificação.

\subsection{Características Gerais do Local do Conjunto Habitacional}

O conjunto habitacional foi projetado em uma área de terra do município de São Lourenço do Oeste, que está localizado ao Noroeste do Estado de Santa Catarina, divisa com o estado do Paraná, na Faixa de Fronteira Brasileira, a $110 \mathrm{~km}$ da Argentina. Possui uma área de $361,77 \mathrm{Km}^{2}$, com relevo planalto acidentado, e altitude média de 895 metros acima do nível do mar. Está situado a latitude $26^{\circ} 21^{\prime} 14.9^{\prime \prime} \mathrm{S}$ e longitude $52^{\circ} 51^{\prime} 07.7^{\prime \prime} \mathrm{W}$.

$\mathrm{O}$ terreno localiza-se no bairro São Francisco, com área total de $2.503,54 \mathrm{~m}^{2}$. Existem construções que serão relocadas do local. A área do terreno possui um desnível de aproximadamente $10 \mathrm{~m}$. A região é contemplada com energia elétrica e rede de água potável.

\subsection{Clima Local}

São Lourenço do Oeste possui clima subtropical úmido, com verões úmidos devido às massas tropicais instáveis. De acordo com a Classificação climática de Köppen-Geiger possui precipitação abundante em todos os meses do ano, tendo invernos secos. A temperatura média no mês frio é abaixo de $18^{\circ} \mathrm{C}$, a temperatura mínima média em meses de inverno é maior de $-3^{\circ} \mathrm{C}$, e a temperatura média no mês mais quente é igual ou maior do que $22^{\circ} \mathrm{C}$.

Os invernos são acentuadamente frios, ocorrendo geadas. Os ventos são constantes no inverno e no verão. A direção dos ventos predominantes possuem direção Noroeste/Sudoeste, com velocidade média em torno de $7 \mathrm{~m} / \mathrm{s}$.

\subsection{Orientação Solar}

Para definir a disposição dos cômodos da residência, deve ser analisada a posição do sol 
e os horários de maior insolação nas diferentes estações do ano. $\mathrm{O}$ fator de insolação afeta tanto a luminosidade quanto o calor do ambiente. Para a verificação solar, foi observado o comportamento solar utilizando-se do exemplo de carta solar proposto por Lamberts, Dutra e Pereira (1997).

A fachada sul é a que menos recebe insolação, praticamente não a recebendo no outono e no inverno, estando presente no verão apenas no início e no fim da tarde; a fachada leste recebe sol todas as manhãs e em todas as estações do ano; a fachada Oeste recebe sol todas as tardes e em todas as estações do ano; e a fachada norte recebe insolação direta nas quatro estações do ano, sendo considerada a fachada mais privilegiada, tendo o sol mais baixo no inverno, e mais alto no verão, o que indica poucas horas do dia.

\subsection{Análise segundo a NBR 15220-3}

O projeto arquitetônico foi desenvolvido de acordo com a NBR 15220-3, a qual apresenta recomendações e diretrizes para o desempenho térmico de habitações de finalidade social com até três pavimentos, aplicáveis na fase de projeto. Subdividiu-se o território brasileiro em oito zonas homogêneas quanto ao clima, estabelecendo para cada uma dessas oito zonas, diretrizes construtivas para a otimização do desempenho térmico nas edificações, bem como recomendações e detalhamento de estratégias de condicionamento térmico passivo;

A região de Santa Catarina, em que se situa a Cidade de São Lourenço do Oeste, encontra-se na zona bioclimática 2, a qual destaca a cidade de Ponta Grossa. A Figura 2 representa a Zona Bioclimática 2.
Figura 2 - Zona Bioclimática 2

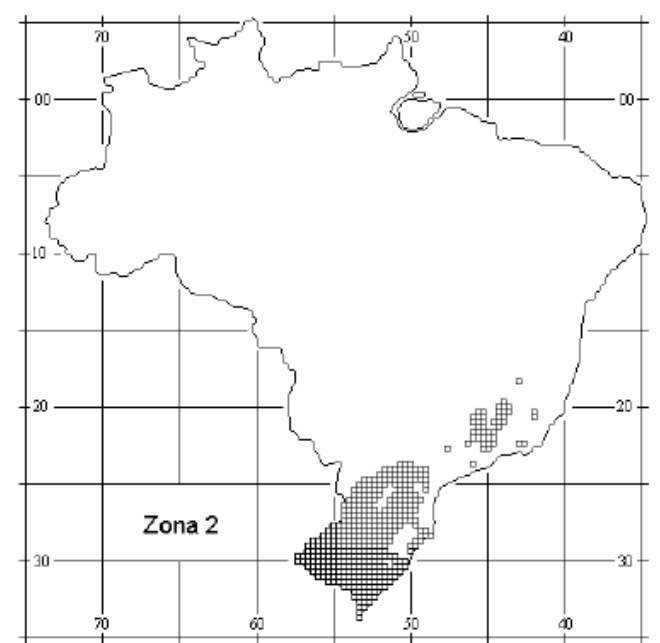

Fonte: NBR 15220

As diretrizes apontadas para a zona bioclimática 2, são aberturas de ventilação de tamanho médio permitindo o acesso do sol durante o inverno. De acordo com a norma brasileira as aberturas médias devem ter a medida em área de $15 \%<\mathrm{A}<25 \%$ em relação a área do piso.

As paredes externas devem ser leves, portanto devem possuir transmitância térmica $\mathrm{U} \leq 3,00$, atraso térmico ${ }^{\varphi} \leq 4,3$ horas, e fator de calor solar $\mathrm{FS}_{\mathrm{o}} \leq 5,0$. Analisadas as sugestões propostas na norma, foi escolhida para este caso a parede com tijolos de 6 furos, com dimensões de $10,0 \times 15,0 \times 20,0 \mathrm{~cm}$, assentados na menor dimensão, com argamassa de assentamento espessura de $1,0 \mathrm{~cm}$, e argamassa de emboço de $2,5 \mathrm{~cm}$, totalizando uma espessura total de $15,0 \mathrm{~cm}$.

As paredes internas devem ser pesadas, portanto devem possuir transmitância térmica $\mathrm{U} \leq 2,20$, atraso térmico $\varphi \leq 6,5$ horas, e fator de calor solar $\mathrm{FS}_{\mathrm{o}} \leq 3,5$. Analisadas as sugestões propostas na norma, foi escolhida para este caso a parede com tijolos de 6 furos, com dimensões de $10,0 \times 15,0 \times 20,0 \mathrm{~cm}$, assentados na maior dimensão, com argamassa de assentamento espessura de $1,0 \mathrm{~cm}$, e argamassa de emboço de $2,5 \mathrm{~cm}$, totalizando uma espessura total de $20,0 \mathrm{~cm}$.

A cobertura deve ser leve isolada portanto devem possuir transmitância térmica $\mathrm{U} \leq$ 2,00 , atraso térmico ${ }^{\varphi} \leq 3,3$ horas, e fator de 
calor solar $\mathrm{FS}_{\mathrm{o}} \leq 6,5$. Mas para este caso foi escolhida a opção de telhado verde, obedecendo as diretrizes apontadas anteriormente.

As estratégias de condicionamento térmico passivo devem permitir a ventilação cruzada no verão, aquecimento solar da edificação no inverno, e vedações internas pesadas.

\subsection{Diretrizes Legais do Município}

Para a realização do estudo, foram utilizadas as normas específicas do município de São Lourenço do Oeste, que são: Plano Diretor Participativo do Município de São Lourenço do Oeste - Lei Complementar $\mathrm{n}^{\circ} 161$, de 21/03/2014, e Código de Edificações do Município de São Lourenço do Oeste - Lei ${ }^{\circ}$ 1.155, de 30/09/98:

A área aonde se situa o terreno pertence à Zona Urbana de Ocupação Prioritária $n^{\circ}$ 4, e no que se refere a taxa de ocupação define que: para residência unifamiliar, a taxa de ocupação não deve ultrapassar $60 \%$ da área do terreno, a taxa de permeabilidade deve ser de no mínimo $15 \%$ da área do terreno, não devendo ultrapassar 4 pavimentos para residências multifamiliares;

Os prismas de iluminação e ventilação terão suas faces verticais definidas pelas paredes externas da edificação e divisas do lote. As dimensões da seção horizontal deverão obedecer às condições mínimas em toda a altura da edificação. Para edificações de até dois pavimentos, as seções mínimas para banheiros e áreas de serviço, poderão ter dimensões mínimas de $1,50 \mathrm{~m}$. E para edificações de até quatro pavimentos, dimensão mínima de $2,00 \mathrm{~m}$.

\section{Proposição Da Moradia De Habitação Social}

A etapa de concepção do projeto foi baseada nos conceitos apresentados neste trabalho, além de buscar priorizar o conforto e a privacidade dos usuários. $\mathrm{O}$ terreno que recebeu o projeto possui três testadas voltadas para as Ruas Joalcides Angheben, Juraci
Vilani, e Arcemir Gonçalves. Para a escolha da Rua onde ficará a frente das Residências, foi empregada a direção dos Ventos Predominantes da Região de São Lourenço do Oeste, a qual tem a direção Noroeste/Sudoeste. Desta forma foi escolhida a direção Noroeste para compor a fachada frontal das residências, a qual corresponde a Rua Juraci Vilani, como pode ser observado na Figura 3. Com o desnível existente no terreno, será possível facilitar a passagem dos ventos em todas as residências.

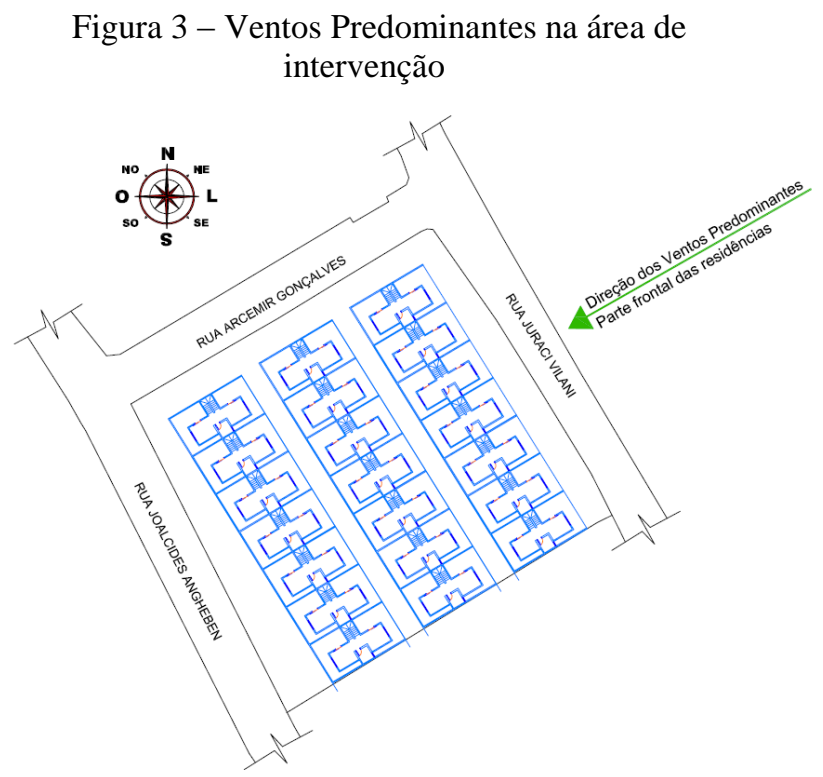

Fonte: Desenvolvido pelos autores

Conforme o Plano Diretor Participativo do Município de São Lourenço do Oeste - Lei Complementar $\mathrm{n}^{\circ} 161$, de 21/03/2014, o recuo frontal para uso residencial deve ser de $4,00 \mathrm{~m}$, e terrenos com mais de uma testada deve ser definido uma via principal, a qual deverá receber o recuo de $4,00 \mathrm{~m}$, e as outras vias receberão recuos de $2,00 \mathrm{~m}$.

O layout foi sendo concebido a partir do posicionamento dos cômodos da residência, sendo a orientação solar e a direção dos ventos fatores primordiais para a escolha da posição dos cômodos, tendo em vista permitir a ventilação cruzada no verão e o aquecimento por isolação no inverno, contendo vedações internas pesadas. 
Para o melhor aproveitamento do terreno, foram escolhidas residências privadas unifamiliares, corrugadas, no formato duplex. Nas Figuras 4 e 5, é possível ver o projeto arquitetônico das residências, e observar que a parte frontal da casa foi projetada voltando-se para o Noroeste, recebendo ventilação constante. No andar térreo a sala de estar fica localizada ao noroeste, e a cozinha voltada ao sudoeste, possuindo aberturas para a ventilação em ambos os lados, sem fechamentos internos permitindo a ventilação cruzada. O mesmo acontece no primeiro andar, tendo o quarto 01 voltado ao noroeste, e o quarto 02 voltado ao sudoeste, com aberturas para a ventilação em ambos os lados. O banheiro e a lavanderia foram projetados para ficarem na divisa do terreno, bem como as escadas, deixando as áreas de maior convivência mais afastadas das divisas, permitindo maior privacidade aos moradores.

Figura 4 - Projeto Arquitetônico Pavimento Térreo

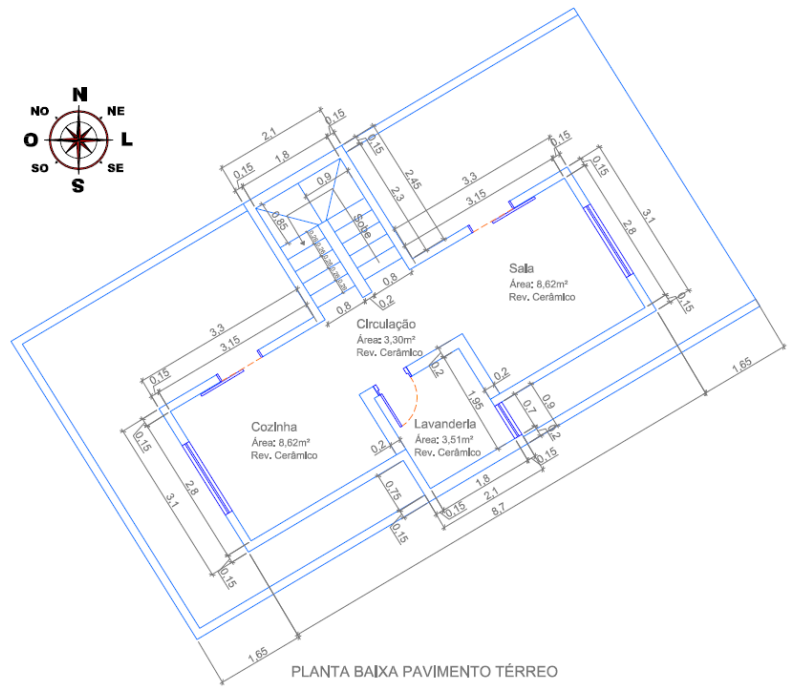

Fonte: Desenvolvido pelos autores
Figura 5 - Projeto Arquitetônico $1^{\circ}$ Pavimento

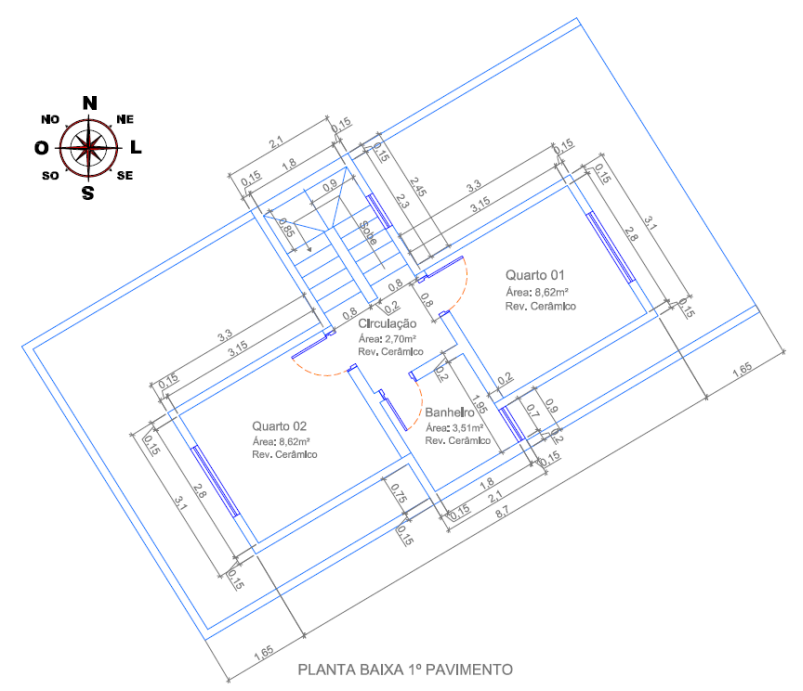

Fonte: Desenvolvido pelos autores

A orientação solar, outro fator importante de análise para a concepção do projeto, pois permite $\mathrm{o}$ aquecimento e iluminação das residências por meio da insolação. A prioridade é obter o máximo de insolação, principalmente nos cômodos mais habitados, desta forma o posicionamento escolhido, permite que todos recebam insolação. A fachada norte possui o maior numero de horas de insolação direta durante todo o ano e contempla todos os cômodos de ambas as residências, exceto na lavanderia e banheiro, que receberão insolação Leste e Oeste, recebendo sol todas as manhãs e todas as tardes. A sala e quarto 01 terão sua orientação mais voltada para o Leste, recebendo sol todas as manhãs, já a cozinha e o quarto 02 terão orientação mais voltada para o Oeste, recebendo sol todas as tardes.

As janelas devem ser dimensionadas para permitir ventilação durante $\mathrm{o}$ verão e a entrada de sol durante o inverno, através delas, é possível ainda iluminar o ambiente. As janelas foram dimensionadas de acordo com o estabelecido na NBR 15220, devendo ter a medida em área de $15 \%<\mathrm{A}<25 \% \mathrm{em}$ relação à área do piso, obedecendo também às dimensões mínimas exigidas pelo Código de Edificações do Município de São Lourenço do Oeste, devendo ter 1/6 do total do cômodo. Como pode ser observado no Quadro 2, para a Sala, Cozinha, Quarto 01 e Quarto 02, foram 
adotadas janelas com $1,50 \mathrm{~m}$ de largura e $1,20 \mathrm{~m}$ de altura, totalizando $1,80 \mathrm{~m}^{2}$. Para o banheiro e lavanderia, foram adotadas janelas com $0,70 \mathrm{~m}$ de largura e $0,85 \mathrm{~m}$ de altura, totalizando $0,60 \mathrm{~m}^{2}$.

\begin{tabular}{|c|c|c|c|c|}
\hline \multicolumn{6}{|c|}{ Quadro 1 - Dimensionamento das Janelas } \\
\hline Cômodo & Área & $\begin{array}{c}\text { Sugerido } \\
\text { NBR }\end{array}$ & $\begin{array}{c}\text { Cód. } \\
\text { Edifica } \\
\text { ções }\end{array}$ & Adotado \\
\hline Sala & $8,62 \mathrm{~m}^{2}$ & $1,29 \mathrm{~m}^{2}$ a $2,15 \mathrm{~m}^{2}$ & $1,44 \mathrm{~m}^{2}$ & $1,80 \mathrm{~m}^{2}$ \\
\hline Cozinha & $8,62 \mathrm{~m}^{2}$ & $1,29 \mathrm{~m}^{2}$ a $2,15 \mathrm{~m}^{2}$ & $1,44 \mathrm{~m}^{2}$ & $1,80 \mathrm{~m}^{2}$ \\
\hline Lavanderia & $3,51 \mathrm{~m}^{2}$ & $0,53 \mathrm{~m}^{2}$ a $0,88 \mathrm{~m}^{2}$ & $0,58 \mathrm{~m}^{2}$ & $0,60 \mathrm{~m}^{2}$ \\
\hline Quarto 01 & $8,62 \mathrm{~m}^{2}$ & $1,29 \mathrm{~m}^{2}$ a $2,15 \mathrm{~m}^{2}$ & $1,44 \mathrm{~m}^{2}$ & $1,80 \mathrm{~m}^{2}$ \\
\hline Quarto 02 & $8,62 \mathrm{~m}^{2}$ & $1,29 \mathrm{~m}^{2}$ a $2,15 \mathrm{~m}^{2}$ & $1,44 \mathrm{~m}^{2}$ & $1,80 \mathrm{~m}^{2}$ \\
\hline Banheiro & $3,51 \mathrm{~m}^{2}$ & $0,53 \mathrm{~m}^{2}$ a $0,88 \mathrm{~m}^{2}$ & $0,58 \mathrm{~m}^{2}$ & $0,60 \mathrm{~m}^{2}$ \\
\hline
\end{tabular}

Fonte: Desenvolvido pelos autores

O fechamento da residência será executado com tijolos cerâmicos revestidos com argamassa e pintura. As paredes aonde existem áreas molhadas, como banheiro, lavanderia e cozinha, receberão revestimento cerâmico na parte interior da residência. $\mathrm{O}$ tipo de fechamento foi escolhido de acordo com o estabelecido na NBR 15220, aonde estabelece que as paredes externas devem ser leves, e serão executadas com tijolos de 6

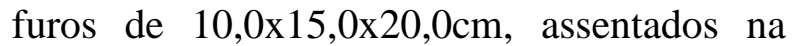
menor dimensão com argamassa de assentamento espessura de $1,0 \mathrm{~cm}, \mathrm{e}$ argamassa de emboço de $2,5 \mathrm{~cm}$, com espessura total de $15,0 \mathrm{~cm}$. As paredes internas devem ser pesadas, executadas com tijolos de 6 furos de 10,0x15,0x20,0cm, assentados na maior dimensão com argamassa de assentamento espessura de $1,0 \mathrm{~cm}$, e argamassa de emboço de $2,5 \mathrm{~cm}$, totalizando uma espessura total de $20,0 \mathrm{~cm}$. Sendo que as paredes que dividem edificações distintas, deverão ter a espessura de 20 centímetros, obedecendo ao Plano Diretor Participativo do Município de São Lourenço do Oeste - Lei Complementar $n^{\circ} 161$, de 21/03/2014.
As portas internas da residência serão de madeira, mantendo o padrão de sustentabilidade e estética da casa, as portas dos quartos terão a largura de $80 \mathrm{~cm}$, já as portas do banheiro e lavanderia terão a largura de $70 \mathrm{~cm}$. As portas que possuem contato com o exterior da residência serão de vidro, com $90 \mathrm{~cm}$ de largura, contribuindo para a luminosidade da residência.

As cores a serem utilizadas devem priorizar a reflexão interna da luz, sendo utilizadas cores neutras e claras em todos os ambientes favorecendo a sensação de iluminação, inclusive os ambientes revestidos com cerâmica.

Para a cobertura das residências a NBR 15220-3, determina que deve ser leve isolada com transmitância térmica $U \leq 2,00$, atraso térmico ${ }^{\varphi} \leq 3,3$ horas, e fator de calor solar $\mathrm{FS}_{\mathrm{o}} \leq 6,5$. Mas para este caso, foi escolhida a opção de telhado verde pelos diversos benefícios que eles proporcionam, tais como a estética diferenciada, a contribuição ecológica, a redução da temperatura nos dias quentes, a melhora na qualidade do ar, e a 
retenção das águas das chuvas reduzindo os riscos de enchentes.

Portanto, acima da laje de concreto deverá ser executada uma camada de impermeabilização que servirá para impedir a infiltração e a perfuração da laje pelas raízes das plantas. A camada de impermeabilização é a mais importante para a execução do telhado verde. Acima deverá ser executado um sistema de drenagem que servirá para absorver o fluxo de água excedente, e promover o escoamento da mesma. O sistema de drenagem adotado será executado com resíduos de demolição, partindo do princípio de reaproveitamento dos materiais e retirada dos mesmos do meio ambiente. A próxima camada a ser recebida será o substrato, camada de solo não muito argiloso, sendo recomendado um total de até $20 \%$, com uma espessura de aproximadamente $15,0 \mathrm{~cm}$. A vegetação adotada deverá ser rasteira e resistente a diferentes temperaturas. Além de contribuir para a estética da residência, o telhado verde ainda representa uma diminuição de custo de $50 \%$ ou mais, em relação a uma estrutura convencional de telhado.

A Figura 6 representa a planta humanizada do pavimento térreo, aonde podemos observar com maior precisão a disposição dos cômodos. A sala de estar fica posicionada na parte frontal da residência e a cozinha nos fundos, com aberturas para ventilação de tamanho médio, não havendo separação com parede entre ambas permitindo a ventilação cruzada entre os cômodos. As vedações internas são pesadas, com espessura de $20 \mathrm{~cm}$, bem como as paredes de divisa entre as edificações, o restante das vedações são leves com espessura de $15 \mathrm{~cm}$, atendendo desta forma as diretrizes apontadas pela NBR 15220-3.

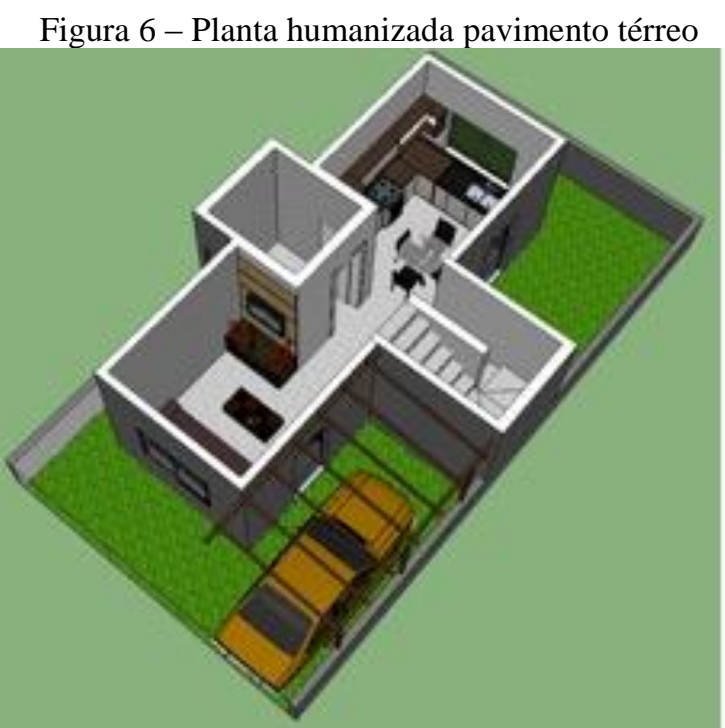

Fonte: Desenvolvido pelos autores

Da mesma forma, a Figura 7 representa a planta humanizada do $1^{\circ}$ Pavimento, aonde podemos observar com maior precisão a disposição dos cômodos. O quarto 01 fica posicionado na parte frontal da residência, enquanto o quarto 02 fica posicionado nos fundos, com aberturas para ventilação são de tamanho médio. Para permitir a ventilação cruzada entre os cômodos, as portas dos quartos devem estar abertas.

\section{Figura 7 - Planta humanizada $1^{\circ}$ pavimento}

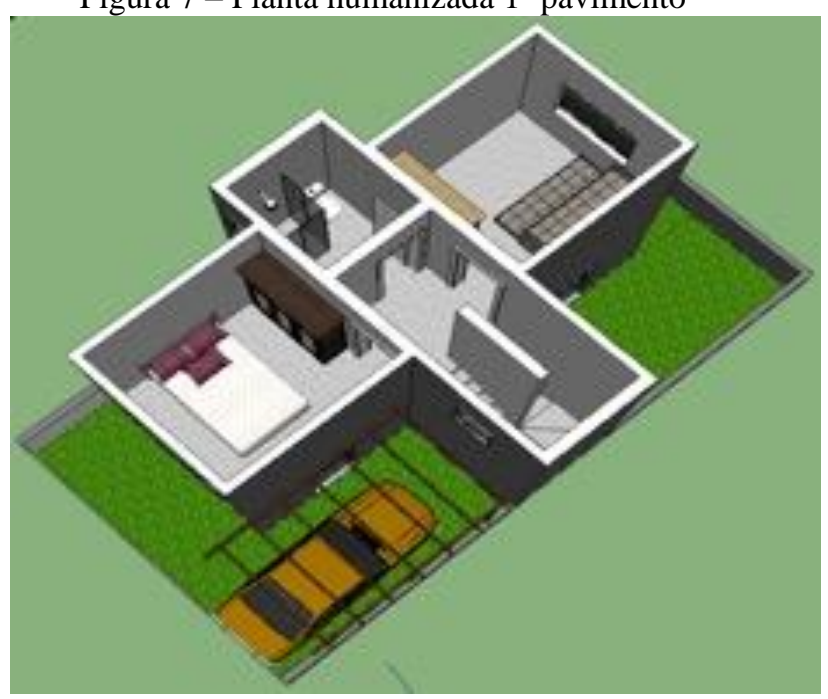

Fonte: Desenvolvido pelos autores

Os telhados verdes, como mostra a Figura 8, surgem como uma alternativa para o meio urbano, sendo uma novidade eficiente e de baixo custo, que vem para melhorar a 
qualidade de vida das pessoas que vivem na residência, e também da sociedade pelo impacto ambiental positivo que causa. Ainda promovem uma significativa valorização do imóvel, contribuindo com a estética da residência. Ainda na Figura 8 , podemos observar a área comum criada nos fundos do terreno, tornando o Conjunto Habitacional mais acolhedor.

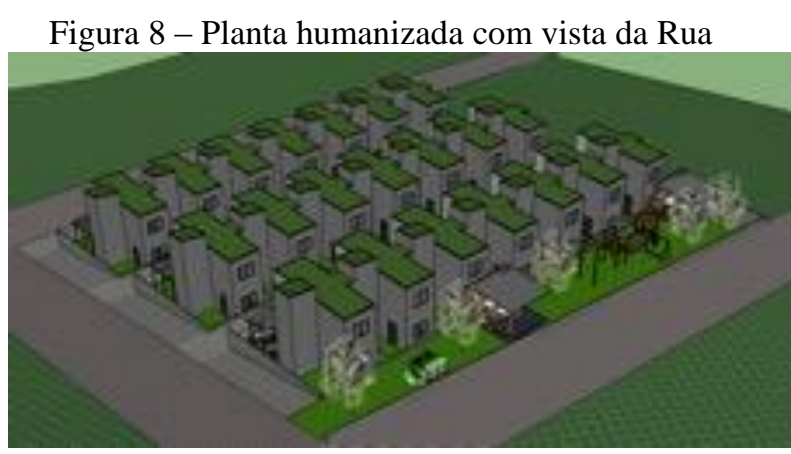

Fonte: Desenvolvido pelos autores

A seguir, na Figura 9 podemos visualizar com mais clareza a disposição das casas no terreno, bem como o desnível existente e os demais aspectos vistos e descritos anteriormente.

Figura 9 - Planta humanizada Vista Superior

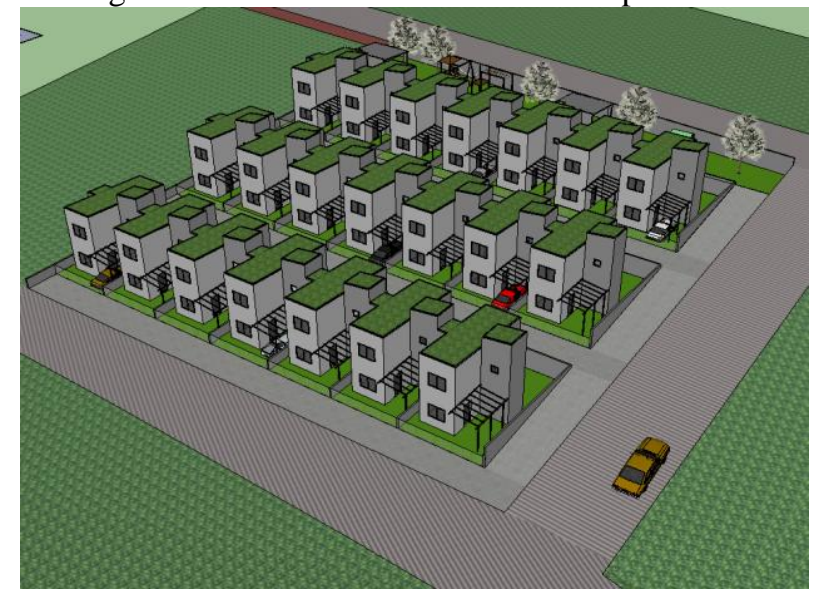

Fonte: Desenvolvido pelos autores

\section{Considerações Finais}

O tema habitação de interesse social é um assunto que vem recebendo espaço, pois tem se construído novas unidades em larga escala, com baixa qualidade, ignorando os preceitos de qualidade de vida dos usuários. As habitações são feitas de forma padronizada, desconsiderando as especificidades regionais, construtivas e térmicas.

Esta pesquisa procura mostrar os benefícios que a arquitetura bioclimática pode oferecer a este tipo de segmento de edificações, sendo a bioclimatologia um estudo que busca harmonizar as construções com o clima e as características locais, alcançando projetos arquitetônicos que priorizem as estratégias naturais de iluminação e climatização, trabalhando num contexto de sustentabilidade. Com o uso da Bioclimatologia é possível obter uma construção eficiente sem alterar os custos.

Para obter uma construção eficiente é preciso conhecer o clima e as características do local de implantação da edificação, a orientação solar e a direção dos ventos predominantes, e seguir as diretrizes apontadas na NRR 15220, sendo que cada zona bioclimática requer diferentes soluções construtivas para obter um bom desempenho térmico, bem como as diretrizes legais e normas municipais.

Procurou-se seguir as estratégias de condicionamento térmico passivo apontadas na NRR 15220-3, devendo permitir a ventilação cruzada no verão, aquecimento solar da edificação no inverno, e vedações internas pesadas, com aberturas de tamanho médio, paredes internas pesadas, e paredes externas leves. A planta arquitetônica das 21 residências projetadas foi sendo definida a partir do posicionamento dos cômodos, que foram determinados a partir da direção dos ventos predominantes para que cada cômodo tivesse ventilação cruzada, aproveitamento da radiação solar para o aquecimento. Para a definição dos telhados saiu-se do padrão, optando-se por um telhado mais ecológico que possui uma série benefícios além do aspecto estético, tais como a redução da temperatura nos dias quentes, eles também absorvem as águas das chuvas e melhoram a qualidade do ar. 
Aliando a arquitetura ao clima, o meio ao planejamento das construções e a associação correta dos materiais, combinando às técnicas corretas, é possível criar ambientes confortáveis aliados à sustentabilidade, proporcionando a satisfação do usuário, sem ocasionar maiores gastos na fase de construção e manutenção, apenas contando com estratégias naturais.

\section{Referências}

BAGNATI, M. M. Zoneamento bioclimático e arquitetura brasileira: qualidade do ambiente construído. 2013. Dissertação (PósGraduação em Arquitetura) Programa de Pesquisa e Pós-Graduação em Arquitetura, UFRGS, Porto Alegre, 2013.

CARDOSO, M. P. Viabilidade do aproveitamento de água de chuva em zonas urbanas: estudo de caso no Município de Belo Horizonte - MG. 2009. Dissertação (Mestrado em Saneamento, Meio Ambiente, e Recursos Hídricos) - Programa de PósGraduação em Saneamento, Meio Ambiente e Recursos Hídricos da Universidade Federal de Minas Gerais - UFMG, Belo Horizonte, 2009.

CATUZZO, H. Telhado Verde: impacto positivo na temperatura e umidade do ar. O Caso da Cidade de São Paulo. 2013. Tese (Doutorado em Geografia Física) - Faculdade de Filosofia, Letras e Ciências Humanas da Universidade de São Paulo - USP, São Paulo, 2013.

COSTA, Soraya P. Eficiência energética em edificações e o uso de fontes alternativas de energia em projetos residenciais urbanos estudo de casos. Minas Gerais, 2007.

Disponível em:

http://www.solenerg.com.br/files/Monografia

Soraya.pdf. Acesso em: 15 de agosto 2013.

CUNHA, Gabriel R., CASTRO, Bruna G., GUIMARÃES, Natanael A., BUZATTO, Marcos V. V. Projeto arquitetônico bioclimático: melhoria da eficiência energética de habitação social em social em município do Nordeste Paulista. IV Congresso Brasileiro e III Congresso IberoAmericano Habitação Social: ciência e tecnologia "Inovação e Responsabilidade". Florianópolis - SC, novembro de 2012. Disponível em:

http://www.artigos.com/components/com_mtr ee/attachment.php?link_id=28283\&cf_id=24. Acesso em: 19 de agosto 2013.

FRANÇA, J. M.; CRUCINSKY, V. M. P. Conceitos de bioclimatologia e sustentabilidade aplicados ao projeto arquitetônico residencial e avaliação do conforto térmico e lumínico da edificação. 2010. 233 f. Trabalho de Conclusão de Curso - Engenharia de Produção Civil, Universidade Tecnológica Federal do Paraná. Curitiba, 2010.

LAMBERTS, R; DUTRA, L; PEREIRA, F. Eficiência Energética na Arquitetura. UFSC/Procel/. Eletrobrás, 1998. Disponível em

http://www.labeee.ufsc.br/arquivos/publicaco es/eficiencia_energetica_na_arquitetura.pdf

LOPES, D. A. R. 2007. Analise do comportamento térmico de uma cobertura verde leve (CVL) e diferentes sistemas de cobertura. Dissertação (Mestrado).

Programa de Pós-graduação em Ciências da Engenharia Ambiental, Escola de Engenharia de São Carlos, Universidade de São Paulo. São Carlos - SP.

MELLO, C. de W. Avaliação de sistemas construtivos para habitações de interesse social. 2004. Dissertação (Mestrado em Engenharia Civil) - Programa de PósGraduação em Engenharia Civil, Universidade Federal do Rio Grande do Sul UFRGS, Porto Alegre, 2004.

MASCARÓ, Lúcia R. de. Energia na edificação: estratégia para minimizar seu consumo. $2^{\text {a }}$ Edição. São Paulo: Projeto Editores Associados Ltda., agosto de 1991. 
NAVAZINAS, V. Arquitetura possível: os espaços comuns na habitação de interesse social em São Paulo. 2007. Dissertação (Mestrado) - Programa de Pós Graduação da Faculdade de Arquitetura e Urbanismo da Universidade de São Paulo, São Paulo, 2007.

ASSOCIAÇÃO BRASILEIRA DE NORMAS TÉCNICAS (ABNT). NBR-

15220: Desempenho Térmico de edificações.

Rio de Janeiro, 2003.

ROTTA, R. Desempenho térmico das edificações multifamiliares de interesse social em conjuntos habitacionais na cidade de Santa Maria - RS. 2009. Dissertação (Mestrado em Engenharia Civil) - Programa de Pós-Graduação em Engenharia Civil, UFSM, RS, Santa Maria, 2009.

PINTO, C.F. Em Busca de uma Arquitetura Sustentável: $O$ Uso de fontes alternativas de energia. 2009. Dissertação (Mestrado em Arquitetura e Urbanismo) - Departamento de Arquitetura e Urbanismo da Escola de Engenharia de São Carlos. USP - Universidade de São Paulo, São Carlos - SP, 2009. 